Running head: BROKERS, INTERMEDIARIES, \& BOUNDARY SPANNERS

\title{
Understanding Brokers, Intermediaries, and Boundary Spanners: \\ A Multi-Sectoral Review of Strategies, Skills, and Outcomes
}

\author{
Jennifer Watling Neal, Michigan State University \\ Stephen Posner, University of Vermont \\ Brian Brutzman, Michigan State University
}

Preprint, forthcoming in Evidence \& Policy

Correspondence should be addressed to Jennifer Watling Neal, Michigan State University, Department of Psychology, 316 Physics Rd. Rm. 242, East Lansing, MI, 48824. Email: ineal@msu.edu. 
BROKERS, INTERMEDIARIES, \& BOUNDARY SPANNERS

\begin{abstract}
Background: Brokers, intermediaries, and boundary spanners (BIBS) bridge research and policy or practice, and can elevate the role of evidence in decision-making. However, there is limited integration of the literature across different sectors to understand the strategies that BIBS use, the skills needed to carry out these strategies, and the expected outcomes of these strategies.
\end{abstract}

Aims and Objectives: In this review, we characterize the strategies, skills, and outcomes of BIBS across the literature in education, environmental, health and other relevant sectors.

Methods: We included 185 conceptual and review papers written in English that included descriptions or conceptualizations of BIBS in the context of knowledge transfer or research use in the education, environmental, health, or other relevant sectors (e.g., social services, international development). For each included paper, we extracted and coded information on sector, BIBS strategies, skills, and outcomes.

Findings: Our review revealed five strategies used by BIBS that were emphasized in the literature. Specifically, $79.5 \%$ of papers mentioned facilitating relationships, $75.7 \%$ mentioned disseminating evidence, $56.8 \%$ mentioned finding alignment, $48.6 \%$ mentioned capacity building, and $37.3 \%$ mentioned advising decisions as strategies used by BIBS. Additionally, papers described skills and expected outcomes that were common across these strategies as well as those that were unique to specific strategies. 
BROKERS, INTERMEDIARIES, \& BOUNDARY SPANNERS

Discussion and Conclusions: We discuss implications of these findings for understanding how BIBS interface with knowledge users and producers as well as directions for future research on BIBS and the professionalization of BIBS roles.

Keywords: broker, intermediary, boundary spanner, knowledge exchange, knowledge translation

\section{Key messages:}

- The literature describes five key strategies used by brokers, intermediaries, and boundary spanners.

- Facilitating relationships and disseminating evidence are the most common strategies described.

- Common skills include clear communication and expertise in research, policy, and change processes.

- Common outcomes include increased research uptake, awareness of user needs, and knowledge exchange. 


\section{Understanding Brokers, Intermediaries, and Boundary Spanners:}

\section{A Multi-Sectoral Review of Strategies, Skills, and Outcomes}

\section{Background}

Policymakers and practitioners face societal challenges such as combating climate change, responding to the COVID-19 pandemic, and seeking racial justice where decision-making benefits from the integration of evidence. However, there is recognition that the exchange of evidence between researchers and policymakers or practitioners is complex, and may involve individuals and organizations serving in broker, intermediary, or boundary spanner (BIBS) roles (Bednarek et al. 2018; Bornbaum et al. 2015). BIBS are critical for bridging research and policy or practice, and can elevate the role of evidence in decision-making. However, there is limited integration of the literature across the education, environmental, and health sectors to understand the strategies that BIBS use, the skills needed to carry out these strategies, and the outcomes of these strategies.

Understanding BIBS requires clear definitions of these roles (Mackillop et al. 2020; Neal et al. 2021). A recent systematic review examined definitions of BIBS across 277 articles in multiple sectors, providing evidence of distinct patterns in how each role was defined in the literature (Neal et al. 2021). For example, brokers were commonly defined as individuals who engaged in multiple functions including research dissemination, facilitating relationships, and capacity building; intermediaries were commonly defined as organizations who engaged in research dissemination; and 
boundary spanners were commonly defined as individuals or organizations involved in facilitating relationships. Additionally, different roles were disproportionately used in different sectors (brokers in health articles, intermediaries in education articles, and boundary spanners in environmental articles). Like Neal et al. (2021), we use the acronym BIBS throughout this paper as shorthand to describe our interest in strategies that cut across definitions of brokers, intermediaries, and boundary spanners. We adopt a broad definition of BIBS that includes individuals or organizations engaged in any of these roles (broker, intermediary, boundary spanner) and in any type of "work to enable exchange between the production and use of knowledge to support evidence-informed decision-making in a specific context" (Bednarek et al. 2018, para. 7). We also define knowledge producers as those individuals or organizations involved in the creation of research evidence (e.g., researchers; research institutes) and knowledge users as individuals or organizations whose decision-making is informed by research evidence (e.g., practitioners, policymakers, non-profit organizations).

Some prior reviews of BIBS have been broad by focusing on definitions across multiple sectors (Neal et al., 2021) whereas other prior reviews of BIBS have been deep by focusing on BIBS' strategies, skills, and outcomes in a single sector (Bornbaum et al. 2015; Cranley et al. 2017; Elueze 2015; Van Eerd et al. 2016) or using a single method (Long et al. 2013). We aim to provide a review that is both broad and deep by characterizing strategies, skills, and outcomes of BIBS across the literature in multiple sectors (e.g., education, environment, health, social services, international development, and communications). This is necessary for several reasons. First, because research on BIBS has often occurred within particular sectors, there have been 
limited opportunities for cross-sectoral discussions about commonalities in strategies, skills, and outcomes. A multi-sectoral review can help identify these commonalities and encourage the cross-fertilization of ideas across sectors. Second, integrating the literature across multiple sectors can identify critical gaps in understanding BIBS and provide future directions for the practice of BIBS. Third, a better understanding of BIBS' strategies, skills, and outcomes can help improve BIBS' practice. Specifically, with this understanding, leaders in funding communities, government, academia, and nongovernmental organizations (NGOs) are better positioned to identify ways to effectively support and institutionalize critical BIBS roles.

In this multi-sectoral review, we examine 185 conceptual and review papers about BIBS to address the following questions: (1) What BIBS strategies are emphasized in the literature? (2) What skills are necessary to engage in BIBS strategies? and (3) What are the expected outcomes of BIBS strategies? In answering these questions, our goal is to integrate the literature across sectors rather than compare and contrast findings between sectors. Expanding prior work (e.g., Bornbaum et al. 2015; Ward et al. 2009), we identify five main strategies used by BIBS: disseminating evidence; facilitating relationships; building capacity; advising decisions; and finding alignment. Across sectors, we explore the skills and outcomes that were common across BIBS strategies as well as those that were unique to specific strategies. We also identify future directions for research and practice with an emphasis on ways to support and institutionalize the work of BIBS. 


\section{Method}

To complete our multi-sectoral review, we relied on guidance from the Preferred Items for Systematic Reviews and Meta-Analyses (PRISMA) statement (Moher et al. 2009).

\section{Eligibility Criteria}

Because we were interested in how papers theorize about and conceptualize BIBS, we limited papers in our review to (1) conceptual and review papers (2) written in English that (3) included descriptions or conceptualizations of BIBS in the context of knowledge transfer or research use in (4) the education, environmental, health, or other relevant sectors (e.g., social services, international development).

\section{Information Sources}

Our review included 185 papers (see Figure 1; a full reference list of all included articles is available at https://osf.io/gi3nh/). To build this sample, we started from the public database of 145 papers reviewed by Neal et al. (2021) (https://osf.io/w5rn2/). Two of the authors of our current review (i.e., Neal and Brutzman) were also authors of the Neal et al. (2021) review. We excluded 26 papers that provided only a cursory discussion of BIBS and added an additional 58 papers mainly from the environmental sector. We shared this preliminary list with several experts (2 in education, 2 in environment, and 1 in health communications), who suggested including an additional 8 papers.

[Figure 1 here]

\section{Data Extraction \& Coding}


BROKERS, INTERMEDIARIES, \& BOUNDARY SPANNERS

For each included paper, we read the full text and coded information on BIBS' strategies, skills, and outcomes. Specifically, we first developed a coding sheet designed to extract relevant information from each article. Next, two study authors used this coding sheet to code the same subset of 15 papers. These authors discussed codes until they reached consensus and used these discussions to refine the coding sheet. Once the two authors had refined the coding sheet, they each coded half of the remaining papers. The complete coding sheet is available at https://osf.io/gi3nh/.

Strategies. We coded which of five different BIBS strategies were mentioned and, when applicable, extracted key quotations and notes that characterized the use of each strategy. Three of these strategies (Disseminating Evidence, Facilitating Relationships, and Building Capacity) are commonly used in prior conceptualizations of BIBS (e.g., Bornbaum et al. 2015; Neal et al. 2021; Ward et al. 2009). Two additional strategies (Advising Decisions and Finding Alignment) emerged during our initial review of the literature.

Skills. We extracted key quotations and notes from each paper on any skills or attributes described as important for carrying out BIBS roles.

Expected Outcomes. We extracted key quotations and notes regarding the outcomes from BIBS work. We focused on identifying the expected outcomes of BIBS' work, including how these outcomes were conceptualized, rather than on the rigorous evaluation of actual outcomes, which were generally not reported in the conceptual and review papers we examined.

\section{Data Synthesis}


BROKERS, INTERMEDIARIES, \& BOUNDARY SPANNERS

To synthesize our findings across included papers, we sorted our coding sheet by strategy and examined descriptions of skills, and outcomes within and across each strategy. This allowed us to characterize skills and outcomes that were common across BIBS strategies as well as those that were unique to particular BIBS strategies. During this exercise, we looked for skills and outcomes that were mentioned across multiple papers. In the results, we provide example references but these references do not represent a comprehensive account of all papers in our review that mentioned a specific strategy, skill, or outcome. Therefore, the number of references should not be interpreted as a proxy for how commonly a strategy, skill, or outcome was mentioned.

\section{Results}

\section{What BIBS Strategies are Emphasized in the Literature?}

Past conceptualizations of BIBS have typically focused on three main strategies: disseminating evidence, facilitating relationships, and building capacity (Bornbaum et al. 2015; Neal et al. 2021; Ward et al. 2009). However, in our review, we identified two additional strategies that are commonly emphasized in the literature: finding alignment and advising decisions. Figure 2 illustrates these five strategies and the extent to which they were discussed in the literature we reviewed. Below, we describe each strategy in detail, focusing on key activities and conceptual issues identified in the literature.

[Figure 2 here]

Facilitating relationships. The most commonly discussed strategy used by BIBS focuses on facilitating relationships between knowledge producers and users (discussed in $79.5 \%$ of articles, Figure 2). Facilitating relationships includes activities 
BROKERS, INTERMEDIARIES, \& BOUNDARY SPANNERS

designed to encourage exchange between different stakeholder groups (e.g., Dagenais et al. 2016; Lomas 2007; Robeson et al. 2008). For example, BIBS may organize forums, conferences, or other networking events (Buizer et al. 2016; Glegg \& Hoens 2016; Turnhout et al. 2013) designed to bring together decision makers and researchers, or may use "signposting", where they refer decision makers to "trusted third parties" that can share research (Sharples \& Sheard 2015, p. 585). Additionally, BIBS may facilitate more frequent or higher quality interactions between knowledge producers and users (Newman \& Head 2015; Shaxson et al. 2012).

A BIBS strategy that focuses on facilitating relationships can be conceptualized as building new relationships or strengthening existing ones. Some activities included in this strategy stem from a linkage and exchange model that characterizes communities of knowledge producers and users as disconnected and in need of "activity that links decision makers with researchers, facilitating their interaction so that they are able to better understand each other's goals and professional cultures, influence each other's work, forge new partnerships, and promote the use of research-based evidence in decision making" (Lomas 2007; p. 131). In contrast, other activities included in this strategy stem from a network brokerage model that characterizes communities of knowledge producers and users as indirectly connected by pre-existing individuals or organizations that can be leveraged and strengthened (Berdej \& Armitage 2016; Long et al. 2013; Neal et al. 2015; Yanovitzky \& Weber 2019).

Disseminating evidence. Another strategy of BIBS is disseminating evidence, which involves translating and communicating research evidence to relevant audiences (discussed in $75.7 \%$ of articles, see Figure 2). Activities associated with this strategy 
BROKERS, INTERMEDIARIES, \& BOUNDARY SPANNERS

include tasks related to creating, translating, diffusing, and applying evidence (Bornbaum et al. 2015). For example, BIBS involved in disseminating evidence may include creating research syntheses, summaries, or reviews, translating evidence into plain language, and building platforms for filtering or diffusing evidence (e.g., Armstrong et al. 2013; Cheng 2001; Ward et al. 2009).

A BIBS strategy that focuses on disseminating evidence can be conceptualized as involving unidirectional or bidirectional information flow. This strategy stems from a knowledge management model that views BIBS as occupying a central position in all phases of information flow between knowledge producers and users (Ward et al. 2009). Sometimes the flow of evidence from knowledge producers to users is passive, but more often it is conceptualized as a "push," in which BIBS actively find, summarize, and convey evidence to stakeholders. Although, this may connote a unidirectional process (Shaxson et al. 2012), some have emphasized that bidirectional exchanges that also include information flow from knowledge users to producers can enhance the relevance and utility of evidence (Cvitanovic et al. 2016; Hering 2016; Lemos et al. 2014; Van Kammen et al. 2006). Despite the potential to better inform scientific inquiry and improve outcomes for knowledge users, movement toward bidirectional exchange can be fraught with challenges. As a result, advocates of bidirectionality in fields ranging from international health policy to marine wildlife conservation have stressed the need to systematically lower barriers between researchers and policymakers through the institutionalization of BIBS' practices that routinely promote stakeholder input (Cvitanovic et al. 2016; van Kammen et al. 2006). 
BROKERS, INTERMEDIARIES, \& BOUNDARY SPANNERS

Finding alignment. Finding alignment is another common BIBS strategy that was mentioned in over half of the articles in this review (i.e., 56.8\%, see Figure 2). Finding alignment involves working with both knowledge producers and users to discuss relevant issues, identify problems, and evaluate potential solutions (Dobbins et al. 2009). BIBS often actively engage in activities that mediate differences among stakeholders and create common ground (Pitt et al. 2018; Sarkki et al. 2020). This process can occur with whole groups of knowledge producers and users, or piecemeal with individuals as part of a larger effort to develop a shared agenda.

Alignment can be conceptualized as agreement or shared positions among stakeholder opinions, values, interests, goals, or agendas. BIBS often look for and create alignment among different stakeholders to facilitate opportunities for collaboration and integrate research into decision making. BIBS engaged in finding alignment may shape dialogue by exploring and discussing what is happening in other sectors or clarify common interests and facilitate knowledge exchange between knowledge producers and users. This strategy includes coproduction, in which knowledge producers and users work together to bring together multiple sources of knowledge, expertise, and perspectives to inform decision making. The mediation function of finding alignment can be conceived as creating "arenas for trust building, sense making, and conflict resolution" (Berdej \& Armitage 2016, p. 2). As BIBS engage in activities related to finding alignment, they "develop mutual understanding of stakeholders' goals and contexts" (Bornbaum et al. 2015, para. 3), which can be reflected in shared terminology and language among key individuals and groups (Meyer 2010). 
BROKERS, INTERMEDIARIES, \& BOUNDARY SPANNERS

Capacity building. A capacity building strategy focuses on bolstering the skills, understanding, or self-reliance of those involved in the process of evidence-informed decision making (discussed in $48.6 \%$ of articles, see Figure 2; Bornbaum et al. 2015; Ward et al. 2009). Specifically, this strategy includes activities to build knowledge users' capacity to appraise the validity, trustworthiness, or methods used to produce research evidence (e.g., Armstrong et al. 2013; Dobbins et al. 2009; Olejniczak et al. 2016; Robeson et al. 2008). It also includes technical assistance designed to build knowledge users' capacity to implement evidence-based programs or practices (Jacobs et al. 2005; Lemos et al. 2012; Sharples \& Sheard 2015).

A BIBS strategy that focuses on capacity building can be conceptualized as building knowledge users' capacity to find and use research evidence (e.g., Newman et al. 2012; Taylor et al. 2014) or building knowledge producers' capacity to communicate their research more effectively to knowledge users (e.g., Newman \& Head 2015). A strategy that focuses solely on building the capacity of knowledge users has been critiqued as deficit-oriented, with Ward et al. (2009) noting that "a more positive way of viewing the capacity-building model is in fostering self-reliance in both the researcher and the decision maker, developing the knowledge transfer and communication skills of the former and the analytical and interpretive skills of the latter" (p. 272). Thus, a growing body of literature focuses on how BIBS can improve knowledge producers' ability to engage in applied research and stakeholder engagement as well as their knowledge of policy-making processes (Bednarek et al. 2018; Cvitanovic et al. 2016; Lomas 2007). 
BROKERS, INTERMEDIARIES, \& BOUNDARY SPANNERS

Advising decisions. BIBS focus on advising decisions by using research evidence to directly inform decision making. Although it was less commonly discussed than other strategies, over one-third of the articles in our review described advising decisions as a strategy used by BIBS (i.e., 37.3\%; see Figure 2). Advising decisions can involve explaining choices and trade-offs (Kirchoff et al. 2015) or evaluating the likely impacts of specific decisions (Topp et al. 2018). BIBS can broaden or expand the range of options decision makers consider (Duncan et al. 2020), for example by "navigating options and choices for strategic policy and planning" (Choi et al. 2005, p. 635). BIBS can also focus attention by making the case for considering particular research (Olejniczak et al. 2016) and supporting the role of research in decision making by defending scientific expertise and articulating the scientific basis for sources of information (De Pryck \& Wanneau 2017). BIBS advise decision makers in "accessing, appraising, adapting and applying findings" from research (Mallidou et al. 2018).

Advising decisions is often conceptualized as BIBS serving in an "intermediate position between knowledge production and use" (Turnhout et al. 2013, p. 356). This leads to different roles for BIBS based on power dynamics and interest in directly influencing policy outcomes, for example informing and advising versus advocating and prescribing (Hetemäki 2019). When serving as an "honest broker of policy alternatives" (Pielke 2007), BIBS strive to have unbiased, nonpartisan, and nonadvocacy roles (e.g., Bednarek et al. 2018; DeBray et al. 2014). This requires BIBS to recognize the perspectives and values of actors, as well as their own potential biases (Bednarek et al. 2018). By providing advice that informs rather than determines the outcomes of decisions, BIBS can foster trust among stakeholders (Cvitanovic et al. 2016). While 
BROKERS, INTERMEDIARIES, \& BOUNDARY SPANNERS

serving in a more advocacy-oriented role, BIBS may provide advice aimed at achieving specific policy outcomes. Levin (2013) observes that "while some intermediaries are concerned with the promotion of evidence wherever it leads, others are pursuing their own policy agendas and are more likely to use evidence selectively in pursuit of predetermined agendas" (p. 22). In more advocacy-oriented approaches, BIBS can advise decisions by influencing the policy agenda, mobilizing policymakers to act (Yanovitzky \& Weber 2019), exerting political pressure (Thuy et al. 2010), or swaying political campaign strategies (Taylor \& Doerfel 2003).

\section{What Skills are Necessary to Engage in BIBS Strategies?}

Almost half of the articles included in this review (47.6\%) identified skills needed to engage in BIBS strategies. Some of the skills identified in the literature were common across BIBS strategies whereas other skills were unique to specific strategies (see Figure 2).

Common skills. Across all strategies, the literature emphasized BIBS' ability to communicate clearly in simple language (e.g., Campbell et al. 2011; Cooper \& Shewchuk 2015; Dagenais et al. 2016; Dobbins et al. 2009; Lomas 2007; Robeson et al. 2008). Additionally, expertise in research and policy was described as important for identifying opportunities to bring research into policy conversations and for bridging communities of knowledge producers and users (e.g., Bednarek et al. 2018; Campbell et al. 2011; Cooper 2014; Cranley et al. 2017; Cvitanovic et al. 2016; Hering 2016; Topp et al. 2018). Finally, BIBS' knowledge of change and decision-making processes were described as instrumental to their success in facilitating the use of research in practice 
BROKERS, INTERMEDIARIES, \& BOUNDARY SPANNERS

and policy (e.g., Cvitanovic et al. 2016; Lomas 2007; Olejniczak et al. 2016; Robeson et al. 2008).

Skills for facilitating relationships. Facilitating relationships requires three unique sets of skills: networking skills, interpersonal skills, and matchmaking skills. First, when facilitating relationships, BIBS need to have strong networking skills, including the ability to identify relevant stakeholders (e.g., Bornbaum et al. 2015; Cvitanovic et al. 2016; Dagenais et al. 2016; Kislov et al. 2017; Van Eerd et al. 2016). BIBS also need to be skilled at engaging in intentional interactions with these stakeholder groups (e.g., Hoens et al. 2013; van Enst et al. 2016) and skilled in planning formal and informal events (e.g., Buizer et al. 2016; Glegg \& Hoens 2016; Lomas 2007; Turnhout et al. 2013). Second, when facilitating relationships, BIBS need to possess several interpersonal skills including the ability to establish trust (Cooper 2014; Cvitanovic et al. 2016;

Dobbins et al. 2009), respect for diverse viewpoints (One Earth 2020), and negotiation or conflict resolution skills to balance group expectations and power dynamics (Franks \& Bory 2017; Lacey et al. 2018; Pitt et al. 2018). Third, when building new relationships, BIBS need matchmaking skills to help connect relevant members of communities of knowledge producers and users (Sharples \& Sheard 2015; Shaxson et al. 2012; Sin 2008).

Skills for disseminating evidence. To disseminate evidence, BIBS require skills in scanning the horizon for requisite knowledge to disseminate between knowledge users and producers (e.g., Khoury et al. 2012; Olejniczak et al. 2016). As such, it is crucial that BIBS marshal information from various sources including academic journals and the gray literature. Given the complex nature of the issues that BIBS often face, this 
BROKERS, INTERMEDIARIES, \& BOUNDARY SPANNERS

information could span various scientific disciplines (Gerber \& Raik 2018). BIBS also require skills in synthesizing and translating research evidence. BIBS need to distill vast amounts of information into smaller, more manageable pieces. This process requires discernment on the part of BIBS. During synthesis, evidence is filtered and prioritized according to the potential relevance for knowledge users (e.g., Cheng 2001; Dobbins et al. 2009; Frost et al. 2012; Sharples \& Sheard 2015; Sin 2008; Topp et al. 2018; Van Kammen 2006; Zidarov et al. 2013). Once synthesized, BIBS might also create knowledge products for specific audiences and contexts, perhaps requiring the interpretation and translation of scientific jargon (e.g., Buizer et al. 2016; Cook et al. 2013; Robeson et al. 2008; Meyer 2010). Finally, BIBS require skills in tailoring and packaging information, which involves summarizing evidence from different sources and presenting it in various media formats (e.g., reviews, infographics) to create useful, contextually relevant messages for knowledge users (Bornbaum et al. 2015; Dobbins et al. 2009).

Skills for finding alignment. To be successful in a strategy that emphasizes finding alignment, BIBS need to be able to understand and mediate differences among stakeholder interests and motivations (e.g., Meyer 2010; Pitt et al. 2018), including their own (Bednarek et al. 2018). A key aspect of finding alignment is also to understand the role and power of different stakeholders in complex decision-making contexts. Flexibility and responsiveness to different stakeholders' needs are seen as valuable for BIBS when finding alignment (e.g., Robeson et al. 2008; Rose et al. 2017). BIBS are more effective if they can anticipate the trajectory of decision-making processes, but also remain responsive to emergent new directions (Bornbaum et al. 2015), for example by 
BROKERS, INTERMEDIARIES, \& BOUNDARY SPANNERS

identifying "emerging management and policy issues that research could help to resolve" (Frost et al. 2012, p. 348). Finding alignment also requires BIBS to be able to navigate new social networks and understand when and how to approach decision makers (Dagenais et al. 2016). Understanding subtle nuances in stakeholder dialogues is important for identifying "proper entry points for engagement" (Buizer et al. 2016, para. 48) and strategically "seiz[ing] upon windows of opportunity" (Rose et al. 2017, para. 17). Dobbins et al. (2009) summarize useful skills for BIBS who are finding alignment: the "ability to develop a trusting and positive relationship with end users and to assist them to incorporate research evidence in their policy and practice decisions, while at the same time promoting exchange of knowledge such that researchers and users become more appreciative of the context of each other's work" (para. 4).

Skills for building capacity. To engage in the capacity building of both knowledge users and producers, BIBS need to possess strong teaching and mentoring skills (e.g., Newman et al. 2012; Pitt et al. 2018; Robeson et al. 2008). Related to these skills, BIBS should possess a commitment to lifelong learning (Mallidou et al. 2018) and understand the principles of adult learning (Lomas 2007). Building capacity may also require several domain-specific skills related to research and decision-making processes. For example, BIBS may need specialized knowledge in technology, research methods, and research appraisal (Cheng 2001) as well as expert knowledge in particular research or practice domains (e.g., Robeson et al. 2008). Additionally, a strategy focused on building capacity requires interdisciplinary and cross-cultural comfort. Specifically, BIBS need to possess "a distinctive level of comfort in moving back and forth between what others 
BROKERS, INTERMEDIARIES, \& BOUNDARY SPANNERS

may perceive as intellectual, cultural or practical boundaries between groups" (Meagher \& Lyall 2013, p. 7-8).

Skills for advising decisions. BIBS benefit from particular skills when advising decisions. Stakeholder mapping is a specific skill that BIBS can use to understand the values of various stakeholders affected by decisions. To maintain a role as an honest broker (Buizer et al. 2016), BIBS should aim to promote balanced perspectives across different types of knowledge and establish a clear, consistent role in decision-making processes (Kislov et al. 2017). Additionally, BIBS must accept a high level of responsibility "when altering the evidence base and deciding which research is of suitable quality and relevance to highlight" and "ensuring that this research is summarised accurately, so it does not distort the original findings" (Sharples \& Sheard 2015; p. 581).

\section{What are the Expected Outcomes of BIBS Strategies?}

Over two-thirds of the articles included in this review (68.6\%) described expected outcomes of BIBS strategies. Like discussions of skills, some expected outcomes spanned multiple BIBS strategies whereas other expected outcomes were unique to a specific BIBS strategy (see Figure 2).

Common expected outcomes. Across all strategies, the literature described common expected outcomes for knowledge users, knowledge producers, and the relationship between these two groups. Among knowledge users, BIBS' strategies are anticipated to increase awareness of and access to research (e.g., Armstrong et al. 2013; Cook et al. 2013; Cooper \& Shewchuk 2015) and the use or rate of uptake of research in practice or policymaking (e.g., Lemos et al. 2012; Newman \& Head 2015). 
BROKERS, INTERMEDIARIES, \& BOUNDARY SPANNERS

These strategies are also expected to influence users' perceptions and attitudes about important qualities of research evidence including its relevance, credibility, impartiality, trustworthiness, acceptability, and feasibility (e.g., Bednarek et al. 2018; Duncan et al. 2020). Among knowledge producers, BIBS' strategies are expected to increase awareness of knowledge users' needs (Pitt et al. 2018) and increase engagement with policy and sources of policy expertise (Bednarek et al. 2018). Finally, at the relationship-level, BIBS' strategies are also expected to increase the amount of knowledge exchange between knowledge users and producers (Dagenais et al. 2016; Glegg \& Hoens 2016; Pitt et al. 2018).

Expected outcomes of facilitating relationships. The unique expected outcomes of a BIBS strategy that focuses on facilitating relationships are themselves relational in nature. Specifically, this strategy is expected to lead to increased trust and mutual respect (Posner \& Cvitanovic 2019; Shaxson et al. 2012), improved collaboration and communication (e.g., Dagenais et al. 2016; Elueze 2015; Glegg \& Hoens 2016; Long et al. 2013; Pitt et al. 2018; Posner \& Cvitanovic 2019; van Enst et al. 2016), more balanced power dynamics (Shaxson et al. 2012; van Enst et al. 2016) and more sustained relationships over time (Jacobs et al. 2005). Furthermore, facilitating relationships can lead to improved inclusion of relevant stakeholders (e.g., Cvitanovic et al. 2016; Glegg \& Hoens 2016; Shaxson et al. 2012), access to varied or divergent information (e.g., Elueze 2015; Long et al. 2013; Neal et al. 2015; Posner \& Cvitanovic 2019), improved understanding of diverse perspectives (e.g., Dagenais et al. 2016), and more interdisciplinary interactions (Jacobs et al. 2005). 
BROKERS, INTERMEDIARIES, \& BOUNDARY SPANNERS

Expected outcomes of disseminating evidence. BIBS who disseminate evidence are expected to increase the output of packaged products like literature reviews (e.g., Campbell et al. 2011), influence what evidence is communicated, and contribute to a shift in how research affects policymaker and practitioner agendas (Debray et al. 2014; Lubienski et al. 2016). These dissemination practices might also foster a responsive, bidirectional research process (Bednarek et al. 2018; Cook et al. 2013; Lemos et al. 2014; Shaxson et al. 2012). Finally, this strategy is expected to facilitate an improvement in users' understanding of research evidence (e.g., Bednarek et al. 2018; Cheng 2001; Cooper \& Shewchuk 2015; Olejniczak et al. 2016; van Enst et al. 2016).

Expected outcomes of finding alignment. A BIBS strategy focused on finding alignment can lead to shared agendas for researchers and decision makers (e.g., Lacey et al. 2018; Lemos et al. 2014). These agendas may include common goals, ideas for how to achieve goals, and collaborative activities among knowledge producers and users. Finding alignment creates synergy among stakeholders, for example "between the scientific research conducted and the information needed" (Cook et al. 2013, p. 670). Consensus among stakeholders can be a key outcome (Zidarov et al. 2013), concerning what "constitutes fit for purpose evidence" (Langer et al. 2016, p. 2) or a "mutual understanding about... the type of research that is most needed" (Bednarek et al. 2018, para. 9).

Expected outcomes of capacity building. A BIBS strategy that focuses on building capacity in knowledge users is expected to yield several outcomes among this group including increased confidence and general skills in using research evidence (e.g., Armstrong et al. 2013, Cheng 2001; Taylor et al. 2014). Additionally, capacity building 
BROKERS, INTERMEDIARIES, \& BOUNDARY SPANNERS

among both knowledge users and producers can spark changes in the worldviews of these groups that can ultimately lead to behavior change (e.g., Newman et al. 2012; Olejniczak et al. 2016).

Expected outcomes of advising decisions. A strategy focused on advising decisions can lead to changes in how decision makers use research evidence. Specifically, BIBS' work can affect specific policy outcomes (Levin 2013), the adoption of evidence-based policies as a goal (Franks and Bory 2017), or the application of research results to decision-making contexts (Dagenais et al. 2016). BIBS can create more equitable access to information among stakeholders (Buizer et al. 2016). In the process, they can identify information needs that direct knowledge producers "toward filling critical knowledge gaps" (Hering 2016 p. 364) and advise knowledge users in a way that shapes their interests (Levin 2013).

\section{Discussion}

Across multiple sectors, the literature acknowledges the important role that BIBS play in connecting knowledge producers and users (e.g., Bednarek et al. 2018; Bornbaum et al. 2015). In this review, we integrated this literature to characterize the strategies that BIBS use, the skills required to effectively implement these strategies, and the expected outcomes of these strategies. Understanding these strategies, skills, and outcomes provides insight into the potential value of BIBS in efforts to bridge research and policy or practice. It is also critical for guiding initiatives to support BIBS in their roles and to evaluate the effectiveness of various BIBS strategies. 
BROKERS, INTERMEDIARIES, \& BOUNDARY SPANNERS

Summary of results. We identified five strategies used by BIBS that were emphasized in the literature. Past research often recognized three of these strategies (i.e., facilitating relationships, disseminating evidence, and capacity building; Bornbaum et al. 2015; Neal et al. 2021; Ward et al. 2009). However, our review builds upon this past work by adding two additional BIBS strategies: finding alignment and advising decisions. Finding alignment captures unique aspects of BIBS' work focused on finding common ground, mutual understanding, and shared agendas between knowledge producers and users (Dobbins et al. 2009; Pitt et al. 2018; Sarkki et al. 2020). In describing BIBS' efforts to find alignment, the literature recognizes that BIBS' roles often go beyond a strategy that builds and strengthens relationships between knowledge producers and users to a strategy that encourages joint sense-making between these groups. Advising decisions emphasizes the unique role of BIBS in providing knowledge users with research as well as evidence-informed choices during decision-making processes (e.g., De Pryck \& Wanneau 2017; Kirchhoff et al. 2015). Advising decisions goes beyond disseminating evidence, instead emphasizing BIBS' role as a neutral and "honest broker" who guides decision-making processes using research evidence (Pielke 2007). Gaining a better understanding of these two additional strategies helps to better characterize the diversity of work that BIBS engage in to bridge research and practice or policy.

The five BIBS strategies that we identified were not discussed evenly in the literature. Specifically, facilitating relationships and disseminating evidence were mentioned in over three-quarters of the papers that we reviewed. In contrast, finding alignment (56.8\%), building capacity (48.6\%), and advising decisions (37.3\%) were 
BROKERS, INTERMEDIARIES, \& BOUNDARY SPANNERS

mentioned in fewer papers. This could be because BIBS primarily use these strategies when promoting exchanges among knowledge producers and users. However, a mention of a strategy in the literature is not necessarily a good proxy for how common a strategy is in practice. Alternatively, facilitating relationships and disseminating evidence may be more commonly mentioned because these strategies involve activities (e.g., organizing forums, creating reviews or other knowledge products) that are more easily observed. Differences in the percentages may also reflect how some strategies are not relevant for particular contexts (e.g., advising decisions is not relevant for a context that does not involve people or groups with broad decision-making authority). Finally, it is also possible that facilitating relationships and disseminating evidence are seen as more fundamentally important to the work of BIBS than other strategies, and are thus mentioned more often.

Our review identified a variety of skills needed to engage in BIBS strategies. Some skills (i.e., communicating clearly, possessing expertise in both research and policy, and having knowledge of change processes) are expected to be beneficial across multiple BIBS strategies. However, other skills are expected to be uniquely beneficial for specific BIBS strategies. Some have argued that it is critical to engage in conscious efforts to train and develop a professional workforce of BIBS (Hering 2016). Both the generalized and unique skills that we have identified in this review can inform these professionalization efforts and be integrated into future job descriptions and training protocols for BIBS' roles.

The literature characterized BIBS as agents for social innovation and change (Bornbaum et al. 2015; Hoens et al. 2013). Therefore, it is not surprising that our review 
identified a variety of expected outcomes from BIBS' work, some general and some specific to particular strategies. Because BIBS' work was characterized as bidirectional, the literature included expected outcomes related to changes in both knowledge users (e.g., increased uptake of research in decision making) and knowledge producers (e.g., increased awareness of knowledge users' needs). Additionally, some expected outcomes for BIBS focused on changes in relationships or broader systems (e.g., more balanced power dynamics, increased interdisciplinary interactions). Interestingly, although the majority of papers in our review $(68.6 \%)$ described general or specific expected outcomes of BIBS' work, there is still limited research that systematically tests the effectiveness of BIBS' strategies for these outcomes. Additionally, research that has tested the effectiveness of BIBS' strategies has been inconclusive and has varied in methodological quality (Bornbaum et al. 2015; Taylor et al. 2014).

Limitations and future directions for research and practice. Findings from our review reflect a large multi-sectoral body of literature on BIBS strategies, skills, and outcomes but nevertheless should be interpreted in light of some limitations in scope. First, our review focused only on papers written in English. Given BIBS' potential to address global challenges, future reviews should also consider how BIBS are characterized in literature written in other languages. Second, we focused on identifying skills and outcomes that were common across BIBS strategies or unique to specific strategies. Future reviews may want to take a more nuanced approach that considers whether certain skills and outcomes are relevant to particular subsets of BIBS strategies. Third, we limited included papers to conceptual and review papers. These papers are often written at a high level of generality and do not provide specifics about 
BROKERS, INTERMEDIARIES, \& BOUNDARY SPANNERS

particular initiatives carried out by BIBS. Therefore, this restricted scope does not allow us to differentiate the strategies, skills, and outcomes of BIBS working to advance the agenda of a particular organization from others who might have a wider mandate to disseminate high quality evidence to advance a field more broadly. Future work might address this gap by delving deeper into the specific contexts (e.g., research teams, organizations) where BIBS are located and gathering evidence about how specific projects might call for certain BIBS activities in a given context.

Future research is also necessary to gain a better understanding of the strategies that BIBS employ to bridge the gap between knowledge producers and users. Specifically, future studies could focus on whether the relative frequency with which these strategies appear in the literature maps onto the reality of BIBS' practice. Additionally, future research could also explore the potential complementarity of BIBS strategies (Kislov et al. 2017), examine temporal factors which could necessitate that one strategy is successfully employed before another can be introduced (i.e., facilitating a relationship before advising a decision), or assess whether extant literature adequately captures the emergent interpersonal processes in which BIBS engage.

Future research should examine the potential negative aspects of BIBS strategies, such as the creation of information bottlenecks (Kislov et al. 2017), destructive interference (where the addition of a BIBS strategy that is out of sync with the efforts of knowledge producers or users could actually hinder translation), or the potential erosion of trust in scientific evidence that could result when BIBS eschew impartiality and assume a more advocacy-oriented position (e.g., Debray et al. 2014; Lubienski et al. 2016). As part of this effort, it will also be necessary to critically examine 
the implications of BIBS' positionality for equity and power. BIBS prioritize certain types of evidence in public decision making and practice. Deciding what counts as evidence, who has voice or standing, and who has privilege and access to decision-making bodies or channels of influence are all likely functions. Consequently, a thoughtful exploration of how BIBS might reinforce or dismantle existing power structures in the scientific community and society writ large is necessary. This issue is closely tied to the positionality of BIBS as either "objective" honest broker or "subjective" issue advocate, and likely fluctuates across a spectrum. However, issues of positionality, equity, and power will be a crucial focus of BIBS research moving forward.

Finally, more rigorous research is also needed to translate our understanding of expected outcomes of BIBS strategies into tested outcomes. Ideally, this research should not only test whether BIBS strategies work but should also provide a more comprehensive understanding of what strategies work in different contexts and why they work. Recently published guidelines for selecting evaluation frameworks to understand BIBS and other related knowledge exchange efforts may be particularly helpful for moving in this direction (Louder et al. 2021).

The findings in this review also have implications for practical efforts to create institutional infrastructure that would establish, support, and develop BIBS as a distinct profession. This work will likely need to involve training to build BIBS' skills, incentives for knowledge users and producers, and financial support (e.g., Armstrong et al. 2013; Cvitanovic et al. 2016). Such work would also have to contextualize these efforts with respect to the institutional barriers that often limit communication between knowledge producers and users. For example, the current academic landscape in which knowledge 
BROKERS, INTERMEDIARIES, \& BOUNDARY SPANNERS

producers often operate relies on incentive structures that prize publication over knowledge use (e.g., high paywalls for academic journals, lack of emphasis on knowledge translation, publication requirements for tenure). However, practical efforts to institutionalize a BIBS profession could help move BIBS from the boundary to the center. As society turns toward science for critical solutions to existential problems, the relevance of BIBS will likely continue to grow.

BIBS strategies are key for tackling large scale societal challenges such as climate change, income inequality, racial justice, and the fight against COVID-19. In each case, the magnitude of these challenges necessitates interdisciplinary collaboration within the scientific community as well as bidirectional communication with stakeholders. Positive outcomes will depend on BIBS working with knowledge producers to tackle issues of critical importance and facilitating informed decision making for the common good.

Research Ethics Statement: The authors of this paper have declared that research ethics approval was not required since the paper does not present or draw directly on data/findings from empirical research.

Funding Details: Not applicable.

Contributor Statement: JWN and SP conceptualized the research questions and review design. JWN and SP extracted and coded the data from review papers. All authors drafted, reviewed, and revised the manuscript. BB conceptualized and designed Figure 2, with input from JWN and SP. 
BROKERS, INTERMEDIARIES, \& BOUNDARY SPANNERS

Conflicts of Interest: The authors declare that there are no conflicts of interest.

Acknowledgements: We would like to thank Angela Bednarek, Chris Cvitanovic, Elizabeth Farley-Ripple, Caitlin Farrell, and Itzhak Yanovitzky who examined our preliminary list of papers and provided additional suggested papers to include in our review.

Supplementary Data: The completed coding sheet and full list of references included in this review are available in the Open Science Framework repository at https://osf.io/gi3nh/ (Neal, Posner, \& Brutzman, 2021).

\section{References}

Armstrong, R., Waters, E., Dobbins, M., Anderson, L., Moore, L., Petticrew, M., Clark, R., Pettman, T.L., Burns, C., Moodle, M., Conning, R., \& Swinburn, B. (2013) 'Knowledge translation strategies to improve the use of evidence in public health decision making in local government: Intervention design and implementation plan,' Implementation Science, 8(1): 121.

Bednarek, A. T., Wyborn, C., Cvitanovic, C., Meyer, R., Colvin, R. M., Addison, P. F. E., Close, S.L., Curran, K., Farooque, M., Goldman, E., Hart, D., Mannix, H., McGreavy, B., Parris, A., Posner, S., Robinson, C., Ryan, M., \& Leith, P. (2018) 'Boundary spanning at the science-policy interface: The practitioners' perspectives', Sustainability Science, 13(4): 1175-1183.

Berdej, S. M., \& Armitage, D. R. (2016) 'Bridging organizations drive effective governance outcomes for conservation of Indonesia's marine systems', PLoS One, 11(1): e0147142. 
BROKERS, INTERMEDIARIES, \& BOUNDARY SPANNERS

Bornbaum, C.C., Kornas, K., Peirson, L. and Rosella, L.C. (2015) 'Exploring the function and effectiveness of knowledge brokers as facilitators of knowledge translation in health-related settings: a systematic review and thematic analysis', Implementation Science, 10(1): 162.

Buizer, J., Jacobs, K., \& Cash, D. (2016) 'Making short-term climate forecasts useful: Linking science and action', Proceedings of the National Academy of Sciences, 113(17): 4597-4602.

Campbell, D., Donald, B., Moore, G., \& Frew, D. (2011) ‘Evidence check: Knowledge brokering to commission research reviews for policy', Evidence \& Policy: A Journal of Research, Debate and Practice, 7(1): 97-107.

Cheng, G. (2001) 'The shifting information landscape: Re-inventing the wheel or a whole new frontier for librarians', New Library World, 102, 26-31.

Choi, B. C., Pang, T., Lin, V., Puska, P., Sherman, G., Goddard, M., Ackland, M.J., Sainsbury, P., Stachenko, S., Morrison, H. \& Clottey, C. (2005) 'Can scientists and policy makers work together?' Journal of Epidemiology \& Community Health, 59(8): 632-637.

Cook, C. N., Mascia, M. B., Schwartz, M. W., Possingham, H. P., \& Fuller, R. A. (2013) 'Achieving conservation science that bridges the knowledge-action boundary', Conservation Biology, 27(4): 669-678.

Cooper, A. (2014) 'Knowledge mobilisation in education across Canada: A cross-case analysis of 44 research brokering organisations', Evidence \& Policy: A Journal of Research, Debate and Practice, 10(1): 29-59. 
BROKERS, INTERMEDIARIES, \& BOUNDARY SPANNERS

Cooper, A., \& Shewchuk, S. (2015) 'Knowledge Brokers in Education: How intermediary organizations are bridging the gap between research, policy and practice internationally', Education Policy Analysis Archives, 23(118): n118.

Cranley, L. A., Cummings, G. G., Profetto-McGrath, J., Toth, F., \& Estabrooks, C. A. (2017) 'Facilitation roles and characteristics associated with research use by healthcare professionals: A scoping review', BMJ Open, 7(8): e014384.

Cvitanovic, C., McDonald, J., \& Hobday, A. J. (2016) 'From science to action: Principles for undertaking environmental research that enables knowledge exchange and evidence-based decision-making', Journal of Environmental Management, 183: 864-874.

Dagenais, C., McSween-Cadieux, E., Somé, P. A., \& Ridde, V. (2016) ‘A knowledge brokering program in Burkina Faso (West Africa): Reflections from our experience', Health Systems \& Reform, 2(4): 367-372.

DeBray, E., Scott, J., Lubienski, C., \& Jabbar, H. (2014) 'Intermediary organizations in charter school policy coalitions: Evidence from New Orleans', Educational Policy, 28(2): 175-206.

De Pryck, K., \& Wanneau, K. (2017) '(Anti)-boundary work in global environmental change research and assessment', Environmental Science \& Policy, 77: 203210.

Dobbins, M., Robeson, P., Ciliska, D., Hanna, S., Cameron, R., O'Mara, L., DeCorby, K. \& Mercer, S. (2009) 'A description of a knowledge broker role implemented as part of a randomized controlled trial evaluating three knowledge translation strategies' Implementation Science, 4(1): 23. 
BROKERS, INTERMEDIARIES, \& BOUNDARY SPANNERS

Duncan, R., Robson-Williams, M., \& Edwards, S. (2020) 'A close examination of the role and needed expertise of brokers in bridging and building science policy boundaries in environmental decision making', Palgrave Communications, 6(1): 1-12.

Elueze, I. N. (2015) 'Evaluating the effectiveness of knowledge brokering in health research: A systematised review with some bibliometric information', Health Information \& Libraries Journal, 32(3): 168-181.

Franks, R. P., \& Bory, C. T. (2017) 'Strategies for developing intermediary organizations: Considerations for practice', Families in Society, 98(1): 27-34.

Frost, H., Geddes, R., Haw, S., Jackson, C. A., Jepson, R., Mooney, J. D., \& Frank, J. (2012) 'Experiences of knowledge brokering for evidence-informed public health policy and practice: Three years of the Scottish Collaboration for Public Health Research and Policy', Evidence \& Policy: A Journal of Research, Debate and Practice, 8(3): 347-359.

Gerber, L. R., \& Raik, D. (2018) 'Conservation science needs new institutional models for achieving outcomes', Frontiers in Ecology and the Environment, 16(8): 438439.

Glegg, S. M., \& Hoens A. (2016) 'Role domains of knowledge brokering: A model for the health care setting', Journal of Neurologic Physical Therapy, 40(2): 115-123.

Hering, J. G. (2016) 'Do we need "more research" or better implementation through knowledge brokering?' Sustainability Science, 11(2): 363-369.

Hetemäki, L. (2019) 'The role of science in forest policy-Experiences by EFl', Forest Policy and Economics, 105: 10-16. 
BROKERS, INTERMEDIARIES, \& BOUNDARY SPANNERS

Hoens, A. M., Reid, W. D., \& Camp, P. G. (2013) 'Knowledge brokering: An innovative model for supporting evidence-informed practice in respiratory care', Canadian Respiratory Journal, 20(4): 271-274.

Jacobs, K., Garfin, G., \& Lenart, M. (2005) 'More than just talk: Connecting science and decision-making', Environment: Science and Policy for Sustainable Development, 47(9): 6-21.

Khoury, M. J., Gwinn, M., Dotson, W. D., \& Schully, S. D. (2012) 'Knowledge integration at the center of genomic medicine', Genetics in Medicine, 14(7): 643-647.

Kirchhoff, C. J., Esselman, R., \& Brown, D. (2015) 'Boundary organizations to boundary chains: Prospects for advancing climate science application', Climate Risk Management, 9: 20-29.

Kislov, R., Wilson, P., \& Boaden, R. (2017) 'The 'dark side' of knowledge brokering', Journal of Health Services Research \& Policy, 22(2): 107-112.

Lacey, J., Howden, M., Cvitanovic, C., \& Colvin, R. M. (2018) ‘Understanding and managing trust at the climate science-policy interface', Nature Climate Change, 8(1): 22-28.

Langer, L., Tripney, J., \& Gough, D. A. (2016) 'The science of using science: researching the use of Research evidence in decision-making', UCL Institute of Education, EPPI-Centre.

Louder, E., Wyborn, C., Cvitanovic, C., \& Bednarek, A. T. (2021) 'A synthesis of the frameworks available to guide evaluations of research impact at the interface of environmental science, policy and practice', Environmental Science \& Policy, 116: $258-265$. 
Lemos, M. C., Kirchhoff, C. J., Kalafatis, S. E., Scavia, D., \& Rood, R. B. (2014) 'Moving climate information off the shelf: Boundary chains and the role of RISAs as adaptive organizations', Weather, Climate, and Society, 6(2): 273-285.

Lemos, M. C., Kirchhoff, C. J., \& Ramprasad, V. (2012) 'Narrowing the climate information usability gap', Nature Climate Change, 2(11): 789-794.

Levin, B. (2013) 'To know is not enough: Research knowledge and its use', Review of Education, 1(1): 2-31.

Lomas, J. (2007) 'The in-between world of knowledge brokering', BMJ, 334(7585): 129132.

Long, J. C., Cunningham, F. C., \& Braithwaite, J. (2013) ‘Bridges, brokers and boundary spanners in collaborative networks: A systematic review', BMC Health Services Research, 13(1): 158.

Lubienski, C., Brewer, T. J., \& La Londe, P. G. (2016) ‘Orchestrating policy ideas: Philanthropies and think tanks in US education policy advocacy networks', The Australian Educational Researcher, 43(1): 55-73.

MacKillop, E., Quarmby, S. and Downe, J. (2020) ‘Does knowledge brokering facilitate evidence-based policy? A review of existing knowledge and an agenda for future research', Policy \& Politics, 48(2): 335-53.

Mallidou, A. A., Atherton, P., Chan, L., Frisch, N., Glegg, S., \& Scarrow, G. (2018) 'Core knowledge translation competencies: A scoping review', BMC Health Services Research, 18(1): 502.

Meagher, L., \& Lyall, C. (2013) 'The invisible made visible: Using impact evaluations to illuminate and inform the role of knowledge intermediaries. Evidence \& Policy: A 
BROKERS, INTERMEDIARIES, \& BOUNDARY SPANNERS

Journal of Research, Debate and Practice, 9(3): 409-418.

Meyer, M. (2010) 'The rise of the knowledge broker', Science Communication, 32(1): 118-127.

Moher, D., Liberati, A., Tetzlaff, J., Altman, D. G., \& Prisma Group. (2009) 'Preferred reporting items for systematic reviews and meta-analyses: The PRISMA statement', PLoS Medicine, 6(7): e1000097.

Neal, J.W., Neal, Z.P., \& Brutzman, B. (2021) ‘Defining brokers, intermediaries, and boundary spanners: A systematic review', Evidence \& Policy.

Neal, J. W., Posner, S., \& Brutzman, B. (2021, September 1) ‘Understanding Brokers, Intermediaries, and Boundary Spanners: A Multi-Sectoral Review of Strategies, Skills, and Outcomes', Retrieved from osf.io/gj3nh

Neal, Z. P., Neal, J. W., Lawlor, J. A., \& Mills, K. J. (2015) ‘Small worlds or worlds apart? Using network theory to understand the research-practice gap', Psychosocial Intervention, 24(3): 177-184.

Newman, K., Fisher, C., \& Shaxson, L. (2012) 'Stimulating demand for research evidence: What role for capacity-building?' IDS Bulletin, 43(5): 17-24.

Newman, J., \& Head, B. (2015) 'Beyond the two communities: a reply to Mead's "why government often ignores research"', Policy Sciences, 48(3): 383-393.

Olejniczak, K., Raimondo, E., \& Kupiec, T. (2016) ‘Evaluation units as knowledge brokers: Testing and calibrating an innovative framework', Evaluation, 22(2): 168189.

One Earth (2020) 'Navigating the Science-Action Labyrinth', 2: 297-299. 
BROKERS, INTERMEDIARIES, \& BOUNDARY SPANNERS

Pielke Jr., R. A. (2007) The honest broker: making sense of science in policy and politics, Cambridge University Press.

Pitt, R., Wyborn, C., Page, G., Hutton, J., Sawmy, M. V., Ryan, M., \& Gallagher, L. (2018) 'Wrestling with the complexity of evaluation for organizations at the boundary of science, policy, and practice', Conservation Biology, 32(5): 9981006.

Posner, S. M., \& Cvitanovic, C. (2019) 'Evaluating the impacts of boundary-spanning activities at the interface of environmental science and policy: A review of progress and future research needs', Environmental Science \& Policy, 92: 141151.

Robeson, P., Dobbins, M., \& DeCorby, K. (2008) 'Life as a knowledge broker in public health', Journal of the Canadian Health Libraries Association/Journal de l'Association des bibliothèques de la santé du Canada, 29(3): 79-82.

Rose, D. C., Mukherjee, N., Simmons, B. I., Tew, E. R., Robertson, R. J., Vadrot, A. B., Doubleday, R. \& Sutherland, W. J. (2017) 'Policy windows for the environment: Tips for improving the uptake of scientific knowledge', Environmental Science \& Policy.

Sarkki, S., Heikkinen, H. I., Komu, T., Partanen, M., Vanhanen, K., \& Lépy, É. (2020) 'How boundary objects help to perform roles of science arbiter, honest broker, and issue advocate', Science and Public Policy, 47(2): 161-171.

Sharples, J., \& Sheard, M. (2015) ‘Developing an evidence-informed support service for schools-reflections on a UK model', Evidence \& Policy: A Journal of Research, Debate and Practice, 11(4), 577-587. 
BROKERS, INTERMEDIARIES, \& BOUNDARY SPANNERS

Shaxson, L., Bielak, A., Ahmed, I., Brien, D., Conant, B., Fisher, C., \& Phipps, D. (2012, April) ‘Expanding our understanding of $\mathrm{K}^{*}(\mathrm{Kt}, \mathrm{KE}, \mathrm{Ktt}, \mathrm{KMb}, \mathrm{KB}, \mathrm{KM}$, etc.)', In $A$ concept paper emerging from the $K^{*}$ conference held in UNU-INWEH Hamilton, ON.

Sin, C. H. (2008) 'The role of intermediaries in getting evidence into policy and practice: Some useful lessons from examining consultancy-client relationships', Evidence \& Policy: A Journal of Research, Debate and Practice, 4(1): 85-103.

Taylor, M., \& Doerfel, M. L. (2003) 'Building interorganizational relationships that build nations', Human Communication Research, 29(2): 153-181.

Taylor, J.S., Verrier, M. C., \& Landry, M. D. (2014) 'What do we know about knowledge brokers in paediatric rehabilitation? A systematic search and narrative summary', Physiotherapy Canada, 66(2): 143-152.

Thuy, P. T., Campbell, B. M., Garnett, S., Aslin, H., \& Hoang, M. H. (2010) 'Importance and impacts of intermediary boundary organizations in facilitating payment for environmental services in Vietnam', Environmental Conservation, 37(1): 64-72.

Topp, L., Mair, D., Smillie, L., \& Cairney, P. (2018) 'Knowledge management for policy impact: The case of the European Commission's Joint Research Centre', Palgrave Communications, 4(1): 87 .

Turnhout, E., Stuiver, M., Klostermann, J., Harms, B., \& Leeuwis, C. (2013) 'New roles of science in society: Different repertoires of knowledge brokering', Science and Public Policy, 40(3): 354-365. 
BROKERS, INTERMEDIARIES, \& BOUNDARY SPANNERS

Van Eerd, D., Newman, K., DeForge, R., Urquhart, R., Cornelissen, E., \& Dainty, K. N. (2016) 'Knowledge brokering for healthy aging: A scoping review of potential approaches', Implementation Science, 11(1): 140.

van Enst, W. I., Runhaar, H. A., \& Driessen, P. P. (2016) ‘Boundary organisations and their strategies: Three cases in the Wadden Sea', Environmental Science \& Policy, 55: 416-423.

Van Kammen, J., de Savigny, D., \& Sewankambo, N. (2006) 'Using knowledge brokering to promote evidence-based policy-making: The need for support structures', Bulletin of the World Health Organization, 84: 608-612.

Ward, V., House, A., \& Hamer, S. (2009) 'Knowledge brokering: the missing link in the evidence to action chain?' Evidence \& Policy, 5(3): 267-279.

Yanovitzky, I., \& Weber, M. S. (2019) 'News media as knowledge brokers in public policymaking processes', Communication Theory, 29(2): 191-212.

Zidarov, D., Thomas, A., \& Poissant, L. (2013) 'Knowledge translation in physical therapy: From theory to practice', Disability and Rehabilitation, 35(18): 15711577. 
Figure 1. PRISMA flow diagram of literature included in the current review

\section{Neal et al. (2021) Systematic Review}

An (a) English language journal article that is (b) a conceptual paper or literature review and contains (c) "broker" OR "intermediar" OR "boundary spann"” AND (d) "knowledge transfer" OR "knowledge utilization" OR "use of research" OR "research use" OR "use of evidence" OR "evidence use" OR "evidence informed" OR "research informed" OR "research based" OR "evidence based" OR "using research" OR "using evidence" OR "research practice" OR "research to practice"

145 Papers

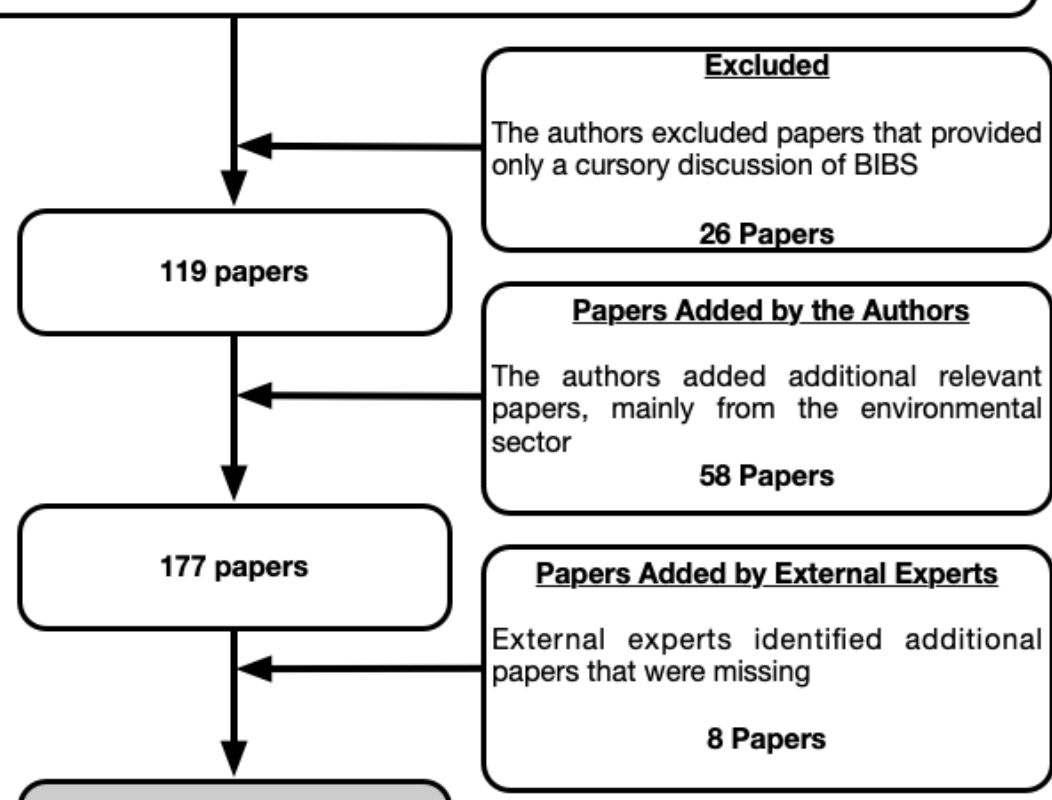

185 final papers included 
Figure 2. BIBS' strategies, skills, and expected outcomes

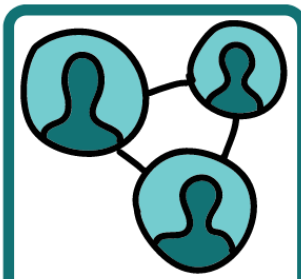

Facilitating Relationships

Building and strengthening ties between knowledge producers and users

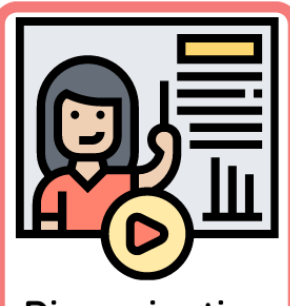

Disseminating Evidence

Translating and communicating evidence to relevant audiences

$75.7 \%$

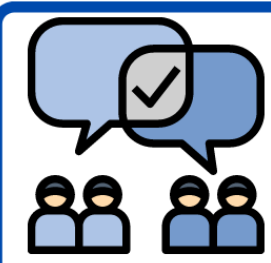

Finding Alignment

Creating common ground between stakeholders with different opinions, values, interests, and cultures

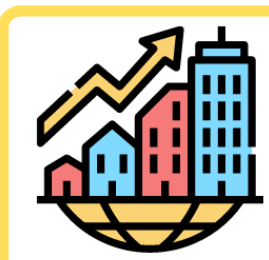

\section{Capacity}

Building

Bolstering the skills, understanding, or

self-reliance of

knowledge producers and users

$48.6 \%$

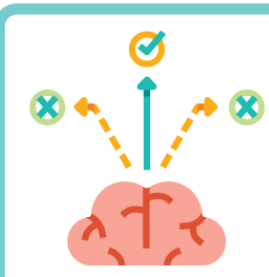

Advising Decisions

Using research evidence to directly inform decision making

$37.3 \%$

\begin{tabular}{|c|c|c|c|c|}
\hline & & $\begin{array}{l}\text { Skills } \\
\text { Common Across Strateg } \\
\text { Communicate Clearly, E} \\
\text { Knowledge of Change Pr }\end{array}$ & $\begin{array}{l}\text { rtise in Research \& Po } \\
\text { esses }\end{array}$ & \\
\hline $\begin{array}{l}\text { - Networking } \\
\text { - Interpersonal Skills } \\
\text { - Matchmaking }\end{array}$ & $\begin{array}{l}\text { - Scanning the } \\
\text { Horizon } \\
\text { - Synthesizing \& } \\
\text { Translating } \\
\text { - Tailoring \& } \\
\text { Packaging }\end{array}$ & $\begin{array}{l}\text { - Mediate Differences } \\
\text { - Understand } \\
\text { Stakeholder Roles \& } \\
\text { Power } \\
\text { - Be Responsive to } \\
\text { Stakeholder Needs } \\
\text { - Navigate Social } \\
\text { Networks }\end{array}$ & $\begin{array}{l}\text { - Teaching \& } \\
\text { Mentoring } \\
\text { - Domain Specific } \\
\text { Skills } \\
\text { - Interdisciplinary \& } \\
\text { Cross-Cultural } \\
\text { Comfort }\end{array}$ & $\begin{array}{l}\text { - Stakeholder } \\
\text { Mapping } \\
\text { - Promote Balanced } \\
\text { Perspectives } \\
\text { - Accept Responsibility } \\
\text { for Accurately } \\
\text { Presenting Evidence }\end{array}$ \\
\hline
\end{tabular}

\begin{tabular}{|c|c|c|c|c|}
\hline & & \multicolumn{3}{|c|}{$\begin{array}{l}\text { Outcomes } \\
\text { Common Across Strategies: } \\
\text { Access to Research, Use of Research, Improved Perceptions of Research } \\
\text { Evidence, Awareness of Knowledge Users' Needs, Knowledge Exchange }\end{array}$} \\
\hline $\begin{array}{l}\text { - Trust } \\
\text { - Collaboration } \\
\text { - Balanced Power } \\
\text { Dynamics } \\
\text { - Inclusion of } \\
\text { Stakeholders } \\
\text { - Access to Varied } \\
\text { Information } \\
\text { - Understanding of } \\
\text { Diverse } \\
\text { Perspectives for } \\
\text { Knowledge Users } \\
\text { \& Producers }\end{array}$ & $\begin{array}{l}\text { - More Packaged } \\
\text { Products } \\
\text { - Change in } \\
\text { Knowledge Users' } \\
\text { Agendas } \\
\text { - Responsive } \\
\text { Research Process }\end{array}$ & $\begin{array}{l}\text { - Shared Agendas } \\
\text { - Synergy } \\
\text { - Consensus } \\
\text { Among } \\
\text { Stakeholders }\end{array}$ & $\begin{array}{l}\text { - Confidence \& } \\
\text { Skills for } \\
\text { Knowledge Users } \\
\text { - Change in World } \\
\text { Views \& Behavior } \\
\text { for Knowledge } \\
\text { Users and } \\
\text { Producers }\end{array}$ & $\begin{array}{l}\text { - Improved Policy } \\
\text { Outcomes } \\
\text { - More Equitable } \\
\text { Access to } \\
\text { Evidence }\end{array}$ \\
\hline
\end{tabular}

